\title{
Experience in Developing Land Degradation Neutrality Concept in the Russian Federation
}

\author{
German Kust ${ }^{1}$, Olga Andreeva ${ }^{1}$, Vasiliy Lobkovskiy ${ }^{2}$, and Jamal Annagylyjova ${ }^{3}$ \\ ${ }^{1}$ Institute of Geography, Russian Academy of Sciences \\ ${ }^{2}$ FSBIS Institute of Geography of the Russian Academy of Sciences \\ ${ }^{3}$ Secretariat of the Convention on Biological Diversity
}

January 22, 2022

\begin{abstract}
The paper overviews and summarizes the results of the developing a methodology for the land degradation neutrality (LDN) assessment basing on LDN-based studies at national, regional and local levels in Russia. The review of more one hundred available publications in Russian language over the past 6-7 years allowed for analysis on the following areas: development of LDN terminology, LDN assessment at the different levels, adapting transition matrix; application of global and national LDN indicators; using the LDN concept for economic valuation of land, estimating LDN baseline, and using LDN as an integral indicator for sustainable land management. With the LDN concept the issue of land degradation (LD) has gone beyond the limited scope of desertification and drylands, and enlarged the concept of "rational" or "effective" land use and land management dominated in Russia. The LDN concept has been broadened with the introduction of the LDN Index proposed to evaluate the rate of LDN achievement; proposal on reconstructing transition matrices and adding specific land cover sub-categories; approach of integrating traditional national sectoral systems for assessing land quality with an LDN add-on; justification for using additional and specific LDN indicators at national and subnational level (soil erosion, aridity, soil salinity, soil depletion, etc.); importance of factoring natural background trends like climate change, natural succession cycles linked with geological and geomorphological processes; need for using different site-specific LDN baselines, not only those time-based; approaches for LDN-based economic valuation of lands; and the LDN-based typology of SLM practices and models.
\end{abstract}

\section{Experience in Developing Land Degradation Neutrality Concept in the Russian Federation}

KustGerman ${ }^{1}$, kust@igras.ru

Andreeva Olga ${ }^{1}$, andreeva@igras.ru

Lobkovskiy Vasiliy ${ }^{1}$, v.a.lobkovskiy@igras.ru

Annagylyjova Jamal ${ }^{2}$, jamal.annagylyjova@un.org

${ }^{1}$ Institute of Geography, Russian Academy of Sciences

${ }^{2}$ Secretariat of the Convention on Biological Diversity

\section{Introduction}

Adopted in 2015 as a part of the SDG Target 15.3, Land Degradation Neutrality (LDN) is a relatively new but rapidly evolving concept recommended to the countries to assess, plan and monitor the progress towards achieving no net loss of healthy land. The concept is supported by internationally accepted methodology (Cowie et al. 2018; Orr et al. 2017) and is embedded in the UNCCD national reporting. Nevertheless, it is largely based on a theoretical framework and fragmented experience on how to operationalize LDN. 
Practical experience in a number of countries demonstrates conventional national peculiarities important for successful LDN targeting. For example, in South Africa the biome level or landscape process based targets (bush encroachment, alien plant species removal) are more appropriate than location specific targets. The spatial location and extent of degradation differ substantially from the three global indicators suggested for LDN target setting (von Maltitz et al. 2019). For Nigeria it is indicated (Ifejika Speranza, Adenle, and Boillat 2019) that "current institutional arrangements are largely unconducive and incoherent for operationalizing LDN"; land pollution and gully erosion are suggested as further relevant indicators for LDN. In Germany (Wunder and Bodle 2019) it is proposed to develop a "concept for a new LDN indicator, which uses land use categories as a possible proxy to differentiate likely impacts on soil. Each land use category is assigned a certain soil value that represents the exposure to soil threats". (Verburg et al. 2019) demonstrate the lack of LDN integration into national land use plans as well as little consideration for land governance and land tenure issues.

In Russia the impetus for the LDN concept development was two main projects, and the authors of this work were directly involved in: the UNCCD LDN target setting programme (2016-2017) and the Project of Russian Science Foundation (RSF) "The development of the novel concept of land degradation neutrality to assess the effectiveness of the approaches for sustainable land use and climate change adaptation" (2018-2020). The concept development was supported by the Scientific Coordination Center for Combating Desertification of the Institute of Geography of the Russian Academy of sciences through data collection for three National reports (National report 2018, 2019, 2021) devoted to land degradation, desertification and drought respectively, and for the national communications within the UNCCD PRAIS2 (2014-2015) and PRAIS3 (2017-2018) reporting cycles.

Russia (1/8 of earth's land) is a country with high natural diversity, and its experience can be important both at a global and national level. More than one hundred LDN-related scientific works have been published so far in Russian national publications, yet their results, as well as the results of two conferences (Practical Geography, 2018) and (Land Degradation and Desertification, 2020) are not readily available at the international level. Therefore, this paper aims to review the results obtained and consider the directions for their development.

\section{Methods}

The main method was a review of publications by Russian scientists, as well as some works by foreign authors (Belarus, Mongolia, Kyrgyzstan) published in Russian language. In 2018, we were the first with an article on the uncertainties of applying the LDN concept in Russia, which included: diversity of biophysical and socioeconomic conditions, diversity of drivers and processes of LD, and the time period for establishing national LDN baseline in Russia (Kust et al. 2018). Since then, the number of LDN-related scientific publications has sharply increased with growing diverse of topics and ideas for scientific discussion (Figure 1). By now, more than one hundred LDN-related publications have been issued, of which about $90 \%$ appeared since 2018. About $80 \%$ of them are published in Russian, and only $20 \%$ in English.

The review of available publications allowed for analysis on the following areas: (i) development of LDN terminology, (ii) LDN assessment at the different levels, (iii) adaptation of transition matrix; (iv) application of global and national LDN indicators; (v) application of LDN framework for economic valuation of land, (vi) estimating LDN Baseline, and (vii) application of LDN as an integral indicator for sustainable land management.

\section{Results and discussion}

\section{General issues of the LDN concept and its development}

Due to strong national traditions in LD assessment, the LDN concept was initially critically met in Russia. Therefore, a significant number of publications (mainly conference reports) were devoted to conceptual issues. It was important to hand the LDN basic principles over to the scientific community and agree on terminology. These issues were discussed at several international fora in Russia, Kazakhstan, Uzbekistan, which resulted 
in applying the LDN concept to a number of scientific problems at national and international level, both in the field of LD and related problems of biodiversity conservation and adaptation to climate change. In Russia it was reflected in (National report 2018, 2019, 2021) published as comprehensive national reviews on the issues of land degradation, desertification, and drought.

Fierce debates took place around the term LDN, which as part of the SDG 15.3 was translated in Russian as "a world without land degradation", and this did not completely reflect a neutrality mechanism. Therefore, in the Russian-language scientific literature, due to the peculiarities of the translation of the term neutrality , LDN was proposed to translate as a neutral balance of land degradation (Zonn, Kust, and Andreeva 2017)) to underline a phenomenon of net zero concept. The results of scientific discussions on new LDN-related terms were reflected in the (Zonn et al. 2018, Kust et al. 2018c) which, together with national reports, quickly became scientific bestsellers. To a certain extent, these works served as the basis for some changes in Russian regulations: new definition for LD have been proposed (GOST, 2020), the LDN terminology has become firmly established in Russian-language scientific literature. In addition, assessments were carried out on the possible integration of the LDN concept with conventional approaches to LD monitoring.

(Zonn, Kust, and Andreeva 2017) highlighted that the LDN concept has opened a new stage of the desertification paradigm's development, land degradation is now recognized as a global threat and requires global actions by both developing and developed countries regardless their climatic zones. LDN also poses new challenges: the application LDN framework needs taking into account national circumstances; land-based adaptation to climate change has not been clearly disclosed in domestic science, as well as evidence-based information on how desertification and droughts affect ecosystem services and ecological functions; information on social consequences of desertification is still scarce. These issues were recognized at scientific fora, and more than 15 relevant programs and projects were adopted in the Academy of sciences and in universities.

For Russia as a "northern" country it is important, that one of the main results of these efforts and studies in 2014-2021 is that the LDN concept has provided an approach for LD assessment beyond drylands scope limited by the UNCCD "mandate". Also, the traditional concept of "rational and/or effective land use and land management" got a new emphasis related to ideas of sustainability, neutrality and keeping the balance between natural and economic potential of land.

\section{LDN assessment at national, subnational and local level}

First studies of this cycle were devoted to the results from assessing individual territories of the Russian Federation using the basic Trend.Earth Quantum-GIS module (TE, 2018) or author's analogs using three global LDN indicators: dynamics of land cover, productivity and soil organic carbon stock (SOC). The results were quite versatile and contradictory. (Trifonova et al., 2021, 2020) focus on the importance of the watershed approach for identifying the boundaries of territories subject to LDN assessment. The main argument is that the greatest homogeneity of biophysical and geochemical conditions is conserved within river basins, which in turn determines the similarity of ecosystems where the effectiveness of LDN mitigation hierarchy of avoid-reduce-reverse (Orr et al. 2017) can be considered:. However, despite the fact that this approach is valid from an environmental perspective, (Andreeva and Kust 2020), (Kust et al. 2019, Kust et al. 2018b) - demonstrated that for national and subnational reporting purposes, it is more efficient to use administrative units, due to a system of relevant statistical data collected by national agencies.

A preliminary assessment for pilot regions of the European part of Russia (Kust, Andreeva, and Lobkovskiy 2020) demonstrated that the LDN concept and the Trend.Earth platform can be considered as a basis for monitoring degradation processes at sub-national level, thus facilitating effective SLM decisions. At the same time, almost all such studies noted that specific data obtained from global databases differ to various extents from ground and statistical data. Also, the Trend.Earth platform, which uses a relatively low data resolution (250-300 m per pixel) resulted problematic for local assessment due to the possible mismatch of boundaries and erroneous interpretation of satellite imagery (Figure 2). Additional studies displayed that the use of Landsat satellite imagery and neural networks for image interpretation, as well as the clarification of land types list, provide an opportunity to increase the mapping accuracy by at least 70 times and simultaneously 
correct the interpretation of positive and negative dynamics for a specific site (Kust et al. 2021). Although this approach is relatively laborious, it becomes useful for local LDN estimates (Figures 3, 4) (RSF 2020).

National level comparative calculations of the total area of degraded land (SDG indicator 15.3.1) using national statistical data (by summing an area of 'deteriorated' land calculated using sectoral methods for different types of land (forest, agricultural, industrial land, etc.)) and Trend.Earth, demonstrated that results obtained by the first method (6.1\% of the total land area) are significantly less than obtained through Trend.Earth (12.3\%) (Andreeva and Kust 2020). This clearly indicates a need for complex harmonizing between the national and global systems since they use different platforms and calculation methods, indicators and systems for obtaining and monitoring data.

Nevertheless, the first experience of comparative analysis for all 85 Russian federal subjects (administrative units) using Trends.Earth (Andreeva and Kust 2020) demonstrates the high efficiency of this method particularly for comparative studies and the identification of "hot spots". For a country like Russia with a high diversity of biophysical and climatic conditions and a variety of economic activities, conducting an overall country assessment of proportion of degraded lands (PDL), with Trend.Earth as a baseline for further calculations $(12.3 \%)$ does not make sense, since for regions it varies from $67 \%$ to less than $1 \%$. In this respect considering the trade-off activities within the whole country as a compensatory scheme for LD does not correspond the LDN principle. Eight federal subjects, where the PDL is less than $2 \%$ and the proportion of stable and improved land is high, can be considered as having achieved LDN. At the same time, in another 8 federal subjects with a high concentration of agricultural lands the PDL is very high. From this perspective, a country assessment covering large territories in general may be quite satisfactory and tends to zero in the long term. However, one of the key requirements for LDN is not met: "counter balancing should occur only within individual land types, distinguished by land potential, to ensure "like-for-like" exchanges" (Orr et al. 2017).

(Kust, Andreeva, and Lobkovskiy 2020) proposed using an "LDN Index" for the overall comparative assessment of regions. This index indicates the difference between improved and degraded lands as an intermediate stage in achieving LDN and demonstrates the effectiveness of land policy and practice within a certain territory. (Andreeva and Kust 2020) calculated the Index for all administrative units of the Russian Federation: for Russia in total the LDN Index averages $25.7 \%$, and for individual regions it varies from $-57 \%$ to $+96 \%$ (Figure 5). According to this Index, the "hottest" spots in Russia are the territories of the South and Volga federal districts.

\section{Adapting transition matrix}

The Trend.Earth platform by default uses expert matrices to diagnose trends in land cover change (degradation, stable, improvement) and productivity dynamics (improving, stable, stable but stressed, early decline, declining). The experience of using default matrices for pilot territories (administrative units or individual farms) revealed that the greatest challenge was interpretating transitions between the categories of treecovered, grasslands, croplands and artificial lands (Ptichnikov and Martynyuk 2020), (Kust et al. 2019). Tree-covered lands, as a result of felling in managed forests, often turn into grasslands and then gradually recover. The recovery successions can continue for dozens and hundreds of years and can be further complicated by stages of wetlands and grasslands. For example, as a result of abandonment (Kust, Andreeva, and Cowie 2017) of agricultural land in Russia in late 80s - 90s (there are up to 50 million hectares of abandoned farmland) (National Report 2019), significant areas remain covered with forest vegetation, while in southern regions they turned into unproductive pastures. For these previously productive lands such transformations are negative from an economic viewpoint. In contrary, their return to farmland started in 00-s is characterized by a formal decrease in NDVI, but considered as a positive process from an economic standpoint. Likewise, many of the depleted peatlands in drained wetlands are hot spots for wildfire risks despite possible turning to forests or meadows. Therefore, their artificial re-wetting should be considered a positive change. Finally, many residential areas, especially in arid regions, are largely covered with green vegetation and have a higher productive potential in contrast to the adjacent natural landscapes. Hence, the reconsidering of evaluation matrices is needed, but it should also be respective different regions. For 
example, for individual farm in the Samara region it was demonstrated that a locally adapted matrix can change the assessment results from negative to positive (RSF, 2020). For pilot sites in the Kaliningrad region the opposite situation was observed: with the positive assessment by default, the matrix adjustment and use of additional indicators calculated the PDL to be that of 86.6\%! (Makarov et al. 2021). For the test farm in the Penza region, an increase of the area of degraded lands was also noted after changing the assessment matrix (Makarov et al. 2021a). In addition to tuning transitions between major land types, in many cases it is important to add specific categories (land subtypes). For example, for bushing areas in the Samara and Kursk regions (forest-steppe subzone) it was important to distinguish young (up to 10-15 years old) and mature (over 15-20 years old) forests (IGRAS 2021). For sites in the Volgograd region (dry steppe subzone) the division into irrigated and non-irrigated arable land was important. For the semi-desert Trans-Volga region, it was essential to subdivide pastures by the degree of degradation (Slavko, Kust G. and Andreeva 2022). Ptichnikov et al. 2019) proposed establishing categories for lands with different types of forest regeneration dynamics in the Komi forests (for example, overgrown burned areas and clearings).

Therefore, the reconstruction of transition matrix is an important element to identify critical land cover and land productivity trends. It should be carried out selectively for various locations at local and provincial levels respecting local conditions and adding land-specific sub-categories.

\section{Effectiveness of using global and national LDN indicators}

This cycle of works represents a significant cluster (about 40\%) of the total number of LDN-related publications, and reflect matters such as:

i. Validating indicators obtained from global datasets against national data;

iii. Variability factors for LDN global indicators;

iii. Possible alternative indicators for interpreting the dynamics of LDN global indicators;

iv. The necessity and feasibility of additional LDN indicators (or not using some global data), depending on local perspectives;

v. Ways of selecting a set of indicators considering regional and local peculiarities.

In relation to point (i) it was noted that three global LDN indicators do not much fit national data. At an individual farm level, the discrepancy between the results obtained using global data, data from detailed satellite imagery and ground-based observations can be as high as 20-30\% (Belyaeva et al. 2019) for all three LDN indicators, in particular for SOC. (Lobkovskiy et al. 2022) indicate that the reason is that global LDN indicators reflect dynamics of certain parameters over a certain period of time, while the traditional national system is designed to assess the quality of land suitable for certain purposes (Table 1). In other words, the national system for land monitoring and assessing and existing relevant frameworks are based on sectoral methods of the assessment of land static qualities. This does not require data on comparable LD parameters obtained with a unified methodological platform. Moreover, land quality parameters that have the same names (for example, soil pollution) are often assessed differently in sectoral systems.

Studies related to point (ii) suggest that beyond physical impacts and other human activities, the variability of LDN global indicators is influenced by different combinations of factors such as climate change, natural fluctuations and successions in vegetation, geological and geomorphological processes associated with the development of river basins, and multidirectional trends in the natural development of landscapes in the postglacial epoch (Andreeva and Kust 2019). It has been demonstrated, that natural trends and processes are often more vigorous than anthropogenic ones, and without taking their background into account it is difficult to assess positive or negative land dynamics.

In relation to point (iii), it was demonstrated, that the assessment of land cover dynamics using the traditional national land accounting system does not fully correspond to the land cover classes adopted for estimating LDN (Table 1). In the Russian land cadaster land categories are distinguished according their intended use (forest fund, agricultural, industrial, etc.) and lands based on actual economic use. For example, the forest 
fund convers not only forested areas, but also includes arable lands, wetlands, roads, and other types of 'land'. Statistical accounting for this system is complex and contradictory. In many cases the state of land cover in terms of 'land categories' remains invariant (especially for agricultural lands and forest fund), and the main changes (if any) concern 'lands', which can hardly be traced in state land statistics. Moreover, national statistics records the total actual areas, but do not record the transitions of 'land categories' or 'lands' from one to another. Therefore, without using space monitoring data, it is practically impossible to trace land transitions, and these methods are rarely used at the level of districts and individual farms.

The land productivity assessment through the use of vegetation indices obtained from the interpretation of multispectral satellite images is becoming a common place. However, for these assessment methods, there are also a number of difficulties associated with both the sectoral and biophysical features of different regions. For example, for drylands the NDVI derived from seasonal composites is more important than the annual average. (Zolotokrylin, Titkova, and Cherenkova 2020) discovered that moisture changes in early summer affect the state of vegetation more significantly than those of the full vegetative season. In (RSF 2020) report it was demonstrated that for farmland the NDVI assessments is of little use for irregular crop rotations, since the spectral reflectance of different crops does not repeat in a multi-year cycle. Even for regular crop rotations individual recognition algorithms are required for cycles of different terms. Data on the key crops yield can serve as an alternative, however, they have significant fluctuations depending on the weather conditions of specific years and on applied agricultural techniques and crop varieties, making it difficult to trace the patterns of their dynamics. For boreal forests, it was determined that the increase in biomass corresponded to the NDVI dynamics, but the growth rate decreases in long term, when young forests pass into mature ones. The productivity of a mature forest, calculated by the NDVI, is usually less than the same for young forest, although this does not reflect degradation of forest land. Alternative indicators could be: timber stock, proportion of forest cover, total growth. However, the biggest challenge is NDVI interpretation for abandoned farmland overgrown with weeds, shrubs and trees. The "greenness" of the surface of such lands is in the majority of cases higher than on the adjacent farmland, but from an economic viewpoint these lands are more degraded than the actual arable land.

Estimation of SOC change is a practically insoluble problem at country level: global and national datasets do not correspond each other (National Report 2019). The SOC dynamics in most areas have not been regularly monitored by field observations since 80-s. For those regions where it remains possible (only for farmlands), the SOC dynamics rather than any long-term trends illustrates a short-term perspective of the economic possibilities of farms for the use of organic fertilizers and available agricultural techniques (Bezuglova, Nazarenko, and Ilyinskaya 2020).

For the purposes of local assessment of agricultural and forest enterprises, and in the absence of reliable data, it was demonstrated that individual software tools cannot yet adequately assess carbon exchange processes, especially in steppe and forest-steppe landscapes. However, correctly selected ensembles consisting of simulation models of C-balance and C-calculators supported by field data, are able to successfully solve such problems. (Karelin and Tsymbarovich 2022) determined that if this condition is met, then the net carbon balance of a certain area can serve as an alternative to SOC. The possibilities of replacing the SOC layer in the Trend.Earth model with a carbon balance layer (calculated using Ex-Act tool (FAO, 2021)) for mapping LDN at the individual farm level have been identified (RSF 2020). However, for boreal regions, the situation is more complicated: (Ptichnikov et al. 2019) showed that the net carbon balance cannot be applied as an independent LDN indicator, since it does not consider changes in biodiversity and primary productivity. The simulation models for natural forest dynamics through minimization of forest felling at sites with fireless types of succession accumulating maximum of dead phytomass, could be more applicable.

Point (iv) is related to using additional and alternative indicators, which would allow to more accurately indicate degradation trends in achieving LDN. In this aspect, the soil erosion indicator is the most important for Russia. It can be interpreted in terms of different measures. It is asserted that in Russia the total area of eroded lands and those under the risk of erosion make up more than $50 \%$ of agricultural lands. However, recent studies indicate a decrease in erosion rate and in the total area of eroded land during the last 30-40 
years as a result of abandonment of farmlands and subsequent overgrowth by natural vegetation. Climate change has resulted in a decrease of the depth of soil freezing and the flow of spring runoff, which in turn leads to a decrease in soil erosion. (Tsymbarovich et al. 2020) demonstrate the possibility of using the soil erosion indicator as an important complement to the three global LDN indicators both at the country and local level. At a national and subnational level, soil erosion neutrality can be interpreted through two indices "Rate of soil loss" (ton ha-1 yr-1) and "Total soil loss" (ton yr-1) when using a "one-out-all-out" approach.

(Karelin and Tsymbarovich 2022) demonstrated that soil water erosion indicators, (in particular length\&steepness (LS) factor; the erodibility potential) can also be used for indirect interpretation of SOC, nitrogen and water dynamics, as well as in reduced presence and altered activity of soil microbiota. The authors showed that the LS-factor calculated on the basis of remote sensing data is applicable for the evaluation of erosion hazards, as well as for prediction of carbon content and other related physical, chemical, and biological indicators of arable Haplic Chernozems on a large spatial scale. The spectral characteristics of the soil surface obtained from remote sensing data are less applicable for these purposes.

The indicator of aridity is the next most important indicator for LDN assessment (Kuderina et al. 2020). At a local level, this can be interpreted through measures of atmospheric precipitation (including snow accumulation) and soil moisture in different seasons, which integrally assess the ability to retain moisture during the growing season and thereby determine the heterogeneity of the soil cover and landscape dynamics. A series of drought indicators that ultimately reflect soil degradation through the availability of moisture and nutrients to plants include characteristics such as soil water holding capacity (Shcherba et al. 2016) and compaction (Sorokin and Kust 2018), (Tsymbarovich et al. 2020). Similar approaches are demonstrated in the works of Belarusian researchers (Yatsukhno and Davydik 2018). Such drought indicators are primarily relevant for local LDN estimates.

At a subnational level, an increase in aridity in certain regions, the emergence and growth of "islands of climatic desertification" can also serve as an indicator of land destabilization and degradation. Such impacts of overgrazing were demonstrated in Mongolia and in southeast of European Russia (Zolotokrylin 2019). The area of local lakes can serve as an indirect integral indicator of aridity, climate change and the water availability. For example, the dynamics of feeding mechanisms of lake systems in south-western Siberia and Transcaucasia indicate either a growing aridity (Shaporenko and Abdurashidov 2021) or very moderate and decreased anthropogenic impact (Chernykh et al. 2022). The frequency of forest and steppe fires (Shinkarenko et al. 2022) can also be considered as an additional LDN indicator at national and subnational levels. Importance of drought indicators for monitoring LD processes is reflected in (National report 2021).

Indicators of soil salinity proposed by (Chernousenko 2021), agro-depletion (decrease in the content of basic nutrients), alkalinity (Tsvetnov et al. 2020, Tsvetnov et al. 2021a, Makarov et al. 2021a) can be considered for LDN at different levels. This requires a well-established monitoring system, which is currently under development (Unified system 2021). For forest areas additional LDN indicators were proposed: level of biological diversity (indicated by species diversity of trees and shrubs) (Ptichnikov and Martynyuk 2020), and the types of recovery dynamics (also accompanied by changes in species diversity) (Ptichnikov et al. 2019).

(Zolotov et al. 2020), (Kust et al. 2021) have emphasized the possibility of using the state of protected areas (PA, area in the region and internal stability) to characterize changes in land cover. For example, the total area of PAs in the Altai region due to the establishment of new PAs and expansion of existing PAs will increase from 795.55 thousand hectares or $4.74 \%$ of the region's territory to 1616.6 thousand hectares $(9.6 \%$ of the region's territory) and preserve the most significant natural complexes. A twofold increase in the area of protected areas will undoubtedly contribute to the achievement of LDN.

The last point $(\mathrm{v})$ is focused on selecting a set of indicators taking into consideration regional and local characteristics (Andreeva and Telnova 2018, Kust et al. 2019, 2018a, Lobkovskiy 2020, Lobkovskiy et al. 2020a, Lobkovskiy et al. 2018). It was observed that in the current Russian land registration system and statistics there were no indicators corresponding to LDN indicators used for monitoring LD, except for in 
the case of agricultural lands. In order to integrate land quality indicators used in Russia into the global system, it has been proposed to streamline various sectoral data through a common consistent LDN-based "superstructure" for different sectoral systems. A conceptual scheme of a hierarchical structure for a system of LD indicators in Russia has been developed (Lobkovskiy et al. 2022), including, on one side, dynamic indicators characterizing the achievement of LDN, and on the other side, state indicators characterizing the quality of land (in terms of risks and degradation results) in relation to their respective categories (Figure $6)$.

Using these approaches, a preliminary analysis and selection of indicators for those operating in different sectors was carried out, in order to integrate into the LDN-based global assessment system. The possible indicators are: area of eroded lands, forest cover, average yield, etc. Further ways of integrating national and international systems for assessing LD are as follows: (i) development of a unified national list of indicators and measures for lands of different categories and types of land use; (ii) use of common qualitative scales of indicators while varying the quantitative values of their measurements (by region, industry, land category, etc.); c) use of land quality scales comparative to either best (maximization of indicators) and/or worst (minimization of indicators) sites in a certain locality/region.

\section{Possibilities of using the LDN concept for economic valuation of land}

Economic assessment of lands is essential in the search for additional LDN indicators and measures. Since the concept of LD includes the need for economic approaches (UNCCD 1994), it is difficult to draw a coherent picture of LDN achievement only using biophysical indicators without direct economic assessments in terms of damage-profit, loss-income, dynamics of value and price, etc. (Tsvetnov et al. 2021) emphasized that a significant drawback of the LDN concept is that none of indicators, as well as the PDL indicator, include an economic interpretation. Natural capital is not monetarized, which makes it necessary to reassess degradation using an "external" methodology. In (Orr et al. 2017) the logic of integrated assessment of ecosystem services is announced as it is coming from the LDN definition, however, actually only the productivity of aboveground biomass (estimated by NDVI), is analyzed, and soil features are limited to the carbon stock. (Tsvetnov et al. 2021, Makarov et al. 2021, Makarov et al. 2021a, 2021b, 2021c, Tsvetnov et al. 2020) demonstrate on pilot sites that through soil parameters of agro-depletion (main nutrients, humus, $\mathrm{pH}$ ) or alkalinization the damage can be monetarized and for different sites ranges from 4 to 153 thousand rubles. This calculation of damage includes not only the costs of restoring soil potential, but also the cost of inaction. It is emphasized that this method is most applicable at local level, whilst at a regional level a direct method for calculating the cost of restoring degraded territory is not effective. It is recommended then to apply formulas considering the area, rate of pollution, degradation and littering, as well as the regional economic properties and special land rates assigned by the state regulator.

The development of LDN-based economic assessment is in the early stages, since from the economic science perspective, these approaches are simplified and do not take into account the local characteristics of labor costs, agricultural markets, infrastructure costs and other indicators that affect the economic efficiency of agricultural production in addition to soil properties. The resulting cost distortions are too high, so the damage values obtained by these methods can be applied only under certain conditions. Furthermore, all of these methods also ignore the ecosystem services of lands, which greatly limits the possibilities of their application for solving sustainable development issues. The need to account soil ecosystem services as part of the "loss of profits" was demonstrated by (Tsvetnov et al. 2021).

\section{Estimating LDN Baseline}

(Kust et al. 2018) noted there are three limitations to establishing the LDN baseline as an average value of 15 years prior to the adoption of the SDG Target 15.3, namely: irregular land cover and land productivity dynamics as a result of drastic socio-economic changes and contradictory land reforms since early 1990s; large areas of forests with a longer period of restoration or formation of new plant communities, reaching hundreds of years; long-term "background" processes of natural evolution of landscapes and adaptation to climate change. Since this publication, a large amount of data has been collected, which confirms these 
conclusions on the basis of retrospective analysis of space imagery and scientific archives, studies of evolution and variability of landscapes and their components in different geographical locations, including responses to different natural and anthropogenic impacts. For key sites in forest and agricultural areas an LDN risks assessment against natural land potential was carried out, including forecasting vulnerability for existing land management. At a local level, studies were undertaken to compare results using different basic timelines, as well as using "timeless" baseline options, such as background landscapes or crop yield estimations. (Kust et al. 2019) indicated that the irregular abandonment and subsequent return of farmlands, which is reflected in the NDVI changes during this period, cannot be interpreted for definite. The NDVI time-series of agricultural regions in the southern regions of European Russia, with actively recovered abandoned farmlands in recent time, formally indicate "negative change" in land productivity between 2000 and 2015 as compared to natural vegetation growth during the same period. Studies of LDN dynamics of managed forests in the Russian North (RSF 2020) estimate that despite NDVI changes in forest land becoming noticeable within 15-20 years after felling and fires, especially in pine forests, full restoration of forests occurs only after 100-150 years, and restoration of ecosystem and species diversity requires at least 200-300 years or more (Figures 7, 8).

Even for grasslands a period of 15-20 years is not sufficient for baseline considering the full restoration of natural capital and ecosystem services. In steppe natural ecosystems regeneration takes at least 50-60 years (Kust et al, 2019), and restoration of natural plant communities and soil cover in disturbed tundra ecosystems takes 40-100 years (Sizov et al. 2020). Regeneration of once disturbed ecosystems is often inhibited by other constant and prolonged disturbances, such as forest and grassland fires, pest invasion, etc. In addition, natural forests are practically not restored to their original state: forested areas expand at the expense of pine and soft-wooded broadleaf species, while old areas of native forest consisting of more valuable coniferous and hardwood species have declined.

Complex processes of rapid depletion and degradation and subsequent long-term restoration of terrain ecosystems are reflected in the practice of forensic land use expertise, for which "significant harm", "restoration to baseline" or "full restoration" are among the key concepts, and for which the LDN approach can be useful. (Kutuzova and Kust 2018) highlight that "reclamation" actions to restore the full scope of ecosystem services and social significance of disturbed ecosystems are almost never sufficient to return an area to the "initial state", due to its uncertainty. In fact, we are talking about diverse, albeit complementary, goals of restoration and qualities of disturbed and degraded systems by: (i) restoring initial productivity, (ii) restoring ecological functions, (iii) restoring ecological balance, (iv) eliminating negative impact , (v) termination of the negative processes/functions, (vi) elimination of certain negative qualities/properties, (vii) acquiring certain positive qualities/processes/regimes relative to the initial state, (viii) sustainable state. To reduce the uncertainty in expert decisions, authors propose using the concept of "optimal state" instead of "initial state" when determining the goal of restoration. This can ensure the implementation of a complex of ecosystem functions that best meet the criteria of environmental safety in site-specific conditions. This proposal fits the concept of "compensation for environmental damage" as stated in Russian legislation, as well as the definition of "restoration/rehabilitation" provided in (IPBES 2021). Using the term "optimal state" for LDN estimating purposes helps avoiding contradictions in setting a baseline for most cases.

As noted above, natural trends often dominate over human impacts, therefore land dynamics should consider their background for a baseline setting. Thus, studies of Holocene evolution of landscapes in southern Russia demonstrate that many LD processes are predetermined by the history of landscape development: anthropogenic impacts most likely trigger degradation processes (salinization, alkalinization, deflation) on sites where their natural analogs took place in the past, despite these old processes have been completed and their features being no longer visible. Human attempts to shift the direction of current degradation processes at a local scale (for example, irrigation against salinization) can temporarily decrease their intensity, but often are not able to reverse them with the technologies available (Andreeva and Kust 2019). Therefore, attempts to achieve LDN in such cases is doomed to failure with insufficient investment. Achieving LDN targets at a regional level occurs more rapidly and at a lower cost, especially where there are "positive" Holocene trends. On the contrary, the "genetic memory" of landscapes on negative "degradation" trends complicates the prospect of successfully achieving LDN. 
A baseline can be established by selecting natural "standards" or their human-supported simulations imitating natural systems while preserving ecosystem functions and natural capital (e.g., no-till technology, adaptive farming, pasture rotation, etc.) This hypothesis was tested in protected areas pilots in the Central Chernozem biosphere reserve and the Samarskaya Luka National Park. It was determined (Figure 3) that the PA territories can be considered as observatories for comparative assessments of LDN indicators for adjacent territories. For the studied PAs themselves, the baseline period of 15 years is sufficient to assess their dynamics in the absence of extreme impacts (Kust et al. 2021).

(Lobkovskiy et al. 2020) drew attention to the fact that, in addition to the temporal and ecosystem factors of baseline setting, the duration of baseline period also depends on the spatial and scale factors. For example, if the land quality of individual farmlands can be restored within several years, then it takes decades to recover a sustainable system of agricultural landscapes. If forest ecosystem restoration takes tens of years, then hundreds of years is needed to restore the integrity of fragmented intact forests. It was also demonstrated that the real land quality may not be adequately reflected, since the starting point of the LDN baseline period may not always coincide with the starting point of recovery. In this case averaging indicators provides an incorrect interpretation of LD processes. For example, the LDN estimate for highly degraded landscapes frequently shows stable or positive dynamics, although the functioning of such landscapes and the performance of important ecosystem functions could be unbalanced (RSF 2020). Depending on the LDN targets for different land use types it was proposed to consider a number of baseline states, contained in Russian regulatory documents: "reference state" as a zero level of loss of natural and economic land value, "initial state" as an undisturbed and non-degraded analogue before the start of impact, "basic state" reflecting the start of monitoring, "background (for local and regional purposes)" as a state formed within a complex of natural or human factors typical for given territory.

(RSF 2020) report concluded that in most cases the approaches to establishing the LDN baseline for practical application in Russia at regional and local levels should differ from the 15-year period recommended for global assessment. The selection of baseline parameters depends on the LDN monitoring objectives. For example, for forest lands, these parameters should consider the dynamics of forests assessed on the basis of typology of time series and changes reflecting typical impacts (felling, fires, etc.). Considering that the peak of the negative dynamics of the LDN indicators falls on 0-3 years after clearcutting, and the sustainable recovery of forest stand and biodiversity begins 10-15 years after felling, the periods for establishing LDN baseline indicators are estimated as follows: for carbon flux 15 years, for productivity and biomass stock - up to 100 years, for species diversity and ecosystem $>200$ years (Figure 6). For tundra vegetation impacted by wildfires in North-Western Siberia the minimum period for baseline is determined by a 60-year (Sizov et al. 2020)cycle.

When developing the topic of baseline establishment, both parameters for reference points and required time interval are proposed (Lobkovskiy et al. 2022) to distinct the groups of dynamic and target indicators. Dynamic indicators are useful to define baseline periods for different land use models (for example, 1015 years or others). Target indicators (or State/Quality indicators) are recommended to determine land quality using the principle of "maximizing" parameters, to demonstrate a sustainable/optimal state in terms of the closeness to (attainability) the "best" state (e.g., achieving a certain soil quality, yield potential of crops, allowable forest cut, sustainable functioning of PA ecosystems, etc.). The principle of "minimizing" parameters is also applicable, for example to demonstrate the rate of desertification as "remoteness" from the state of natural deserts or badlands. "Standardization" approach using national environmental norms and standards also can be applied, e.g., for soil pollution or fertility, state of pastures, forest lands, etc.

\section{LDN as an integral indicator for sustainable land management (SLM)}

The achievement of LDN is sufficiently linked with SLM applications to ensure ecological balance, food security and economic efficiency. However, the methods of assessment sustainability and related criteria remains important. It is obvious (and this is emphasized in a large number of works) that SLM approaches and technologies can be considered as a direct tool for achieving LDN, but in many cases the opposite is also true: LDN concept and indicators can be used to assess the sustainability of land use and land management 
(Andreeva et al. 2021; Kust et al. 2017; Orr et al. 2017). Despite the seeming simplicity of this nexus, which was first expressed in (Andreeva and Kust 2014), it appears to be an effective tool for decision makers at national and subnational level. For example, considering the multidirectional variety of degradation and restoration trends in different climatic and economic conditions of Russia's territory, the "LDN Index" serves as a simple and effective tool for indicating SLM, effective land policy and reducing the risk of LD for any region. Negative values of the Index indicate a high proportion of degraded and vulnerable land and the need for sharing SLM good practices (Andreeva and Kust 2020, Kust et al. 2021a). The same principle is useful for individual farms: joint LDN and SLM assessment and mapping conducted in pilot sites of agricultural areas in the Kursk, Samara and Rostov regions demonstrated that territories with a positive LDN Index are characterized by effective SLM practices. For example, reducing soil erosion, decompaction of topsoil and SOC growth in the soils of the Samara region resulted from no-till technology (IGRAS, 2021).

The consistent development of the idea of using LDN for SLM assessment and the analysis of good SLM practices sets in Russia and in the world, have made it possible to classify land management models, and to determine the criteria for the sustainability of land management practices based on the analysis of land natural potential, risks of degradation processes and human impact. A hierarchy of land management practices was described with the determination of categories "practice", "model", "type", and "class" (Andreeva et al. 2021). Fifteen types of land management were combined into four classes, including three classes of models (9 types in total) characterized by SLM practices, and one class (6 types) included practices, which are not sustainable. A detailed analysis of land management types showed that not all practices contribute to LDN achievement, and vice versa, not every LDN case is associated with any SLM model. This seemingly paradoxical and unexpected conclusion allowed us to rethink the SLM-LDN nexus.

Land management practices demonstrate growing human impact on the environment. However, they cannot considerably change dominating natural background processes but may act as triggers for shifting these processes to positive or negative direction and determining the intensity of soil erosion, salinizationdesalinization, compaction-decompaction of soils, accumulation or loss of organic matter, etc. It was further proposed (Andreeva et al. 2022) to assess the "risks of not reaching" LDN due to the weakness of SLM practices against the background of dominating degradation processes. The latter is forming the basis for including the previously mentioned salinity, density, alkalinity, soil erosion as additional LDN indicators. This proposal is fully in line with the LDN response hierarchy and emphasizes that preventing and reducing degradation risks are more effective and less costly compared to land rehabilitation/restoration.

Further analysis puts forward a hypothesis that the achievement of LDN in a certain territory is determined not so much by the coverage of this territory with effective SLM practices, as by keeping an ecological frame of certain SLM type (core SLM areas and networks). Such frames maintain the sustainability of specific SLM models at minimal cost due to high natural potential or efficient land management technologies (Andreeva et al. 2022). These include, for example, agricultural areas using adaptive landscape and soil conservation technologies, networks of forest shelterbelts, hydrological networks of river basins, including their floodplains and valleys, etc. Such frames and core areas contribute not only to reducing LD risks, but also conserving biodiversity and mitigating climate change effects. The development of this hypothesis is the subject of further research.

Application of ecological standards and principles in achieving LDN becomes essential as the UN announced 2021-2030 as a Decade for Ecosystem Restoration. As the world is embracing a new paradigm of ecological restoration, rewilderness and nature-based solutions, some practical tools such as landscape restoration approaches or integrated land use planning (ILUP) could serve as useful decision-making tools which allow for optimization of SLM measures and planning for sustainable multifunctional landscapes. However, the spatial planning tools are not yet sufficiently discussed in the reviewed publications. This is reinforced by the analysis of the LDN targets in twelve countries of Europe and Central Asia (UNCCD 2021) which revealed that ILUP has not been considered as an entry point for LDN implementation. Current LDN targets in these countries largely represent the collection of isolated SLM interventions across various ecosystems.

\section{Conclusion}


LDN is an evolving concept that is gradually moving beyond the originally designated UNCCD framework approaches, and developing in different, often unexpected directions, which is clearly manifested in its interaction with traditional national scientific schools. This paper analyzes the results of the development of the LDN concept in Russia, and in particular, in the Russian-language scientific literature over the past 6-7 years. The main conclusions are that with the application of LDN concept the issue of LD has gone beyond the narrow categorization of desertification, the drylands mandate of the UNCCD, the concept of "rational" or "effective" land use and land management dominated in Russia. LD has now received a new emphasis associated with the ideas of sustainability, neutrality and maintaining the balance between natural and economic potential of land.

Studies of the applicability of LDN methods using three proxy indicators demonstrated that despite the fact that global LD assessment framework requires a thorough harmonization with the national land monitoring systems, the LDN concept along with Trend.Earth plugin could be considered as a holistic and effective decision-support approach and tool for monitoring LD processes at national and sub-national levels. For this purpose and to support decision-making, the LDN Index was proposed, which assesses the degree of LDN achievement in specific territories. Reconstruction of transition matrices for identification of land cover and land productivity changes is an important element in identifying critical trends and should be carried out selectively for various locations, at district and provincial levels respecting local conditions and adding specific land sub-categories.

As the review of publications shows that most attention has been directed to the application of global and national LDN indicators while all three LDN global indicators show substantial deviation with national data. This is underpinned by a different approach of national land assessment which has the task of identifying quality of lands used for certain administrative and economic activities, which leads to an incompatibility between the global dynamic LDN indicators and the national static data. The authors highlight the importance of factoring natural background trends like climate change, natural succession cycles linked with geological and geomorphological processes, which could act as more powerful drivers of change than anthropogenic impact.

At present, in Russia the only effective way to integrate LDN-based approaches and national sectoral systems for assessing land quality is their joint use, simultaneously with separating tasks for each of the assessment systems. This requires the development of an LDN "superstructure", an add-on for different-quality sectoral systems, allowing them to gradually converge through the use of alternative and additional indicators. Soil erosion is the most cited national indicator identified as an additional parameter to assess LDN, followed by the aridity indicator. Soil salinity, biological diversity and land within protected areas are also among the indicators suggested for either specific ecosystems or at sub-national level.

As LD is a multi-dimensional phenomenon relying only on bio-physical indicators, and without the application of economic valuation methods, it does not provide a nuanced picture of LDN attainment. Authors argue that connecting primary land productivity indicators alone to economic value is a drawback of the global LDN methodology and point to a need for applying a broader approach and accounting for total value of ecosystem services.

Attention to the limitations of LDN baseline setting is given by highlighting the main causes as: inconsistency in land cover trends caused by massive land reforms, large forest areas with long recovery period, and long-term landscape Holocene evolution. Authors further discuss the uncertainties in defining "baseline condition", arguing that no intervention can restore ecosystems to their original state, and therefore suggest a definition of "optimal conditions" which can support a series of ecosystem services. Approaches for baseline assessment in Russia should differentiate from the global methodology, particularly at regional and local level. The choice of dynamic and target (benchmark) indicators for LDN baseline assessment depends on the objective of LDN monitoring. In addition, the territory of biosphere reserves is suggested as a benchmark for comparative assessment using LDN indicators for the adjacent areas or for the territories with similar bio-climatic conditions. 
The development of the LDN concept makes it possible to introduce new aspects into the concept of "sustainability" of land management, which contributes to preventing LD and reducing the land potential and the sustainable functioning of the ecosystem as a whole. LDN can serve as an indicator of sustainability of land use within the boundaries of certain territories, as well as a criterion for the SLM typology described in terms of "practice", "model", "type", and "class". Studies of the SLM-LDN interactions led to the conclusion that not all SLM practices contribute to the achievement of LDN, and conversely, not every case of LDN is associated with any SLM model. Based on this, the idea of the importance of assessing the risks of "not achieving" LDN, and the hypothesis of a SLM "frame" and "core areas" important for the achievement of LDN in a certain territory were put forward.

\section{Acknowledgement}

The authors acknowledge the funding from the Ministry of Science and Higher Edication of the Russian Federation and from Russian Science Foundation

\section{Hosted file}

References 30.12 resubmitted.docx available at https://authorea.com/users/456684/articles/ 553679-experience-in-developing-land-degradation-neutrality-concept-in-the-russianfederation

\section{Hosted file}

Table1_Kust_et al LD\&DJ 30 Dec.docx available at https://authorea.com/users/456684/articles/ 553679-experience-in-developing-land-degradation-neutrality-concept-in-the-russianfederation

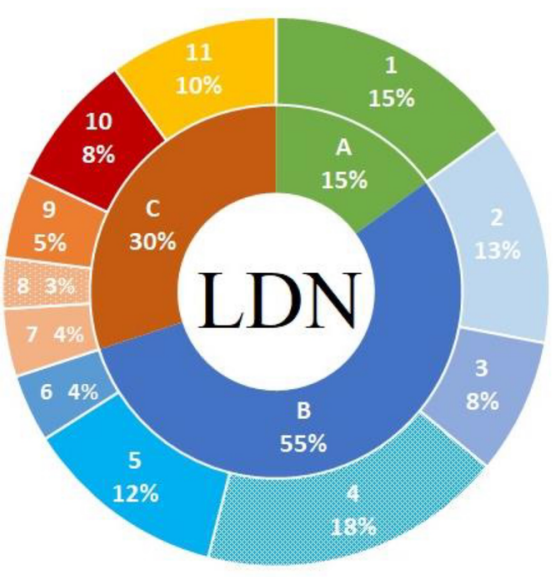

\begin{tabular}{|c|l|}
\hline \multicolumn{2}{|c|}{ A. General issues } \\
\hline 1 & LDN concept and its development \\
\hline 2 & $\begin{array}{l}\text { LDN } \text { LDN assessment methodology } \\
\text { levels }\end{array}$ \\
\hline 3 & $\begin{array}{l}\text { Posssibilities for using default matrices to evaluate } \\
\text { transitions }\end{array}$ \\
\hline 4 & $\begin{array}{l}\text { Effectiveness of using global and national LDN } \\
\text { indicators }\end{array}$ \\
\hline 5 & $\begin{array}{l}\text { Necessity and possibility for additional LDN } \\
\text { indicators }\end{array}$ \\
\hline 6 & Estimating LDN baseline approaches \\
\hline & C. Practical applications of the $\mathbf{L D N}$ concept \\
\hline 7 & $\begin{array}{l}\text { LDN-based approaches for evaluating } \\
\text { land/ecosystem dynamics of boreal and sub-arctic } \\
\text { zones }\end{array}$ \\
\hline 8 & $\begin{array}{l}\text { Using the LDN concept to address climate change } \\
\text { mitigation and adaptation, and biodiversity } \\
\text { conservation }\end{array}$ \\
\hline 9 & $\begin{array}{l}\text { Possibilities for application of the LDN concept for } \\
\text { the economic valuation of land }\end{array}$ \\
\hline 10 & LDN as an integral SLM indicator \\
\hline 11 & $\begin{array}{l}\text { LDN concept as a tool for decision-making in } \\
\text { national state or sectoral policy (use of natural } \\
\text { resources, land monitoring, etc.) }\end{array}$ \\
\hline
\end{tabular}



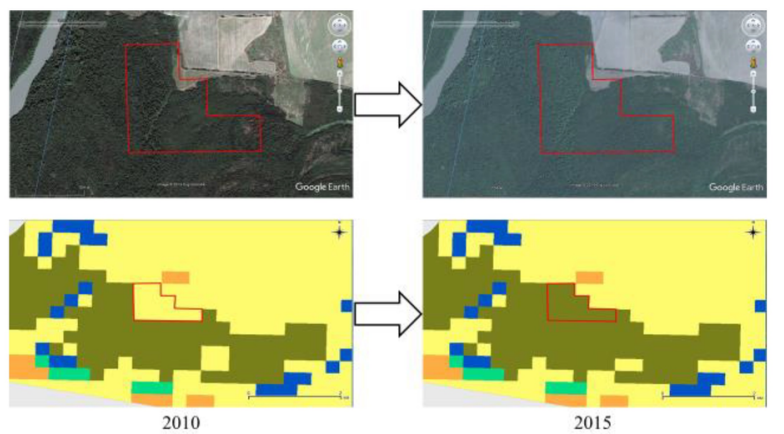

A. Incorrect interpretation of overgrowing of arable land with a constant forest cover
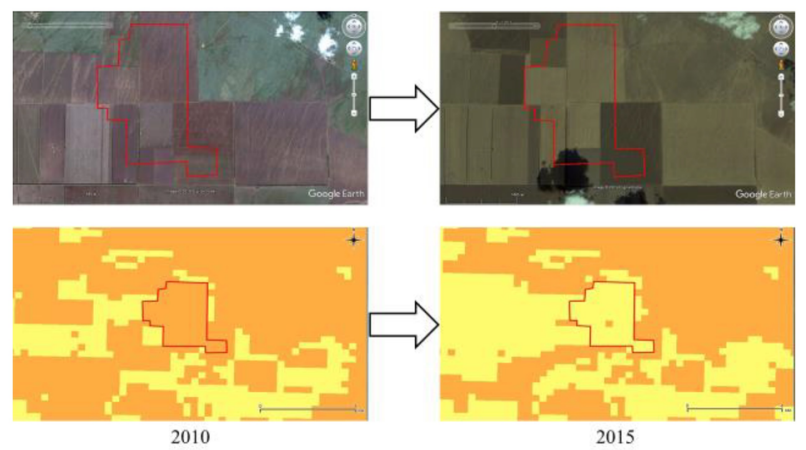

B. Incorrect interpretation of fallow to arable land transition with constant arable land

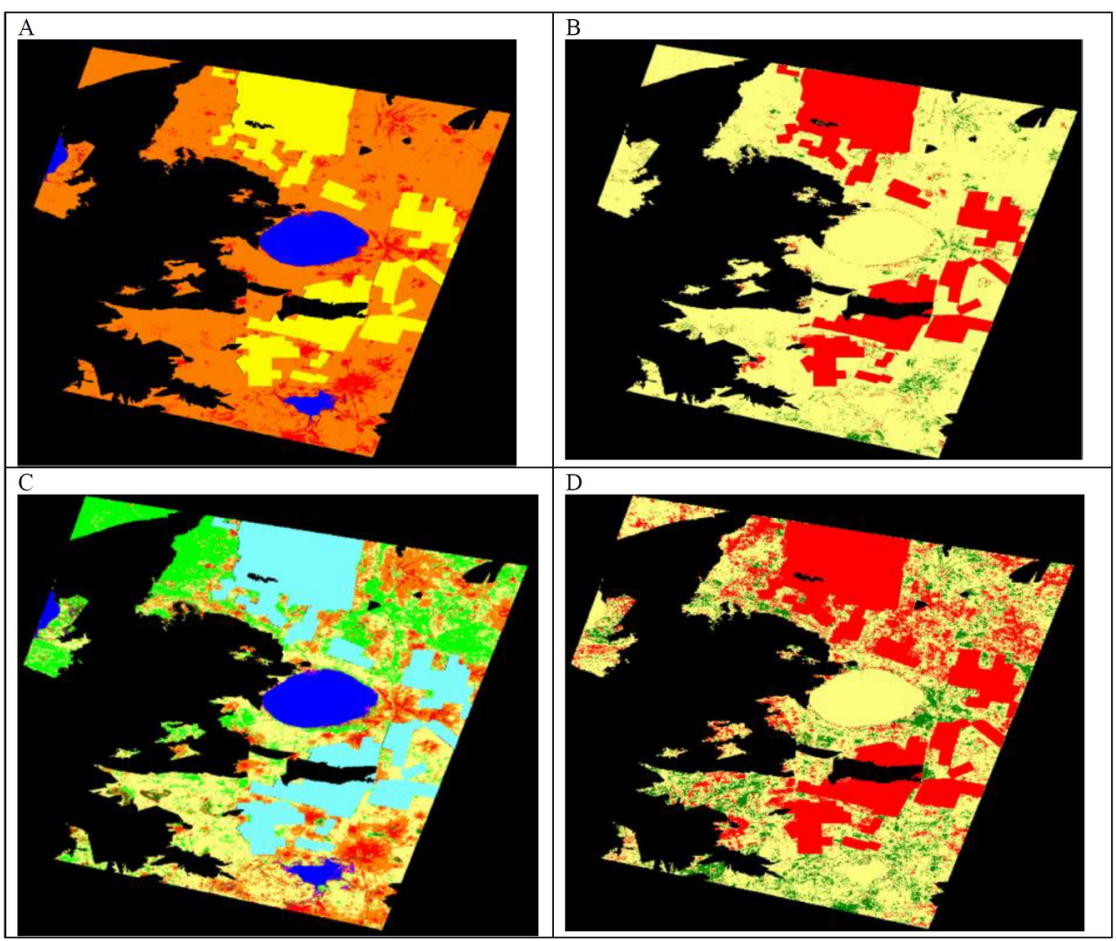



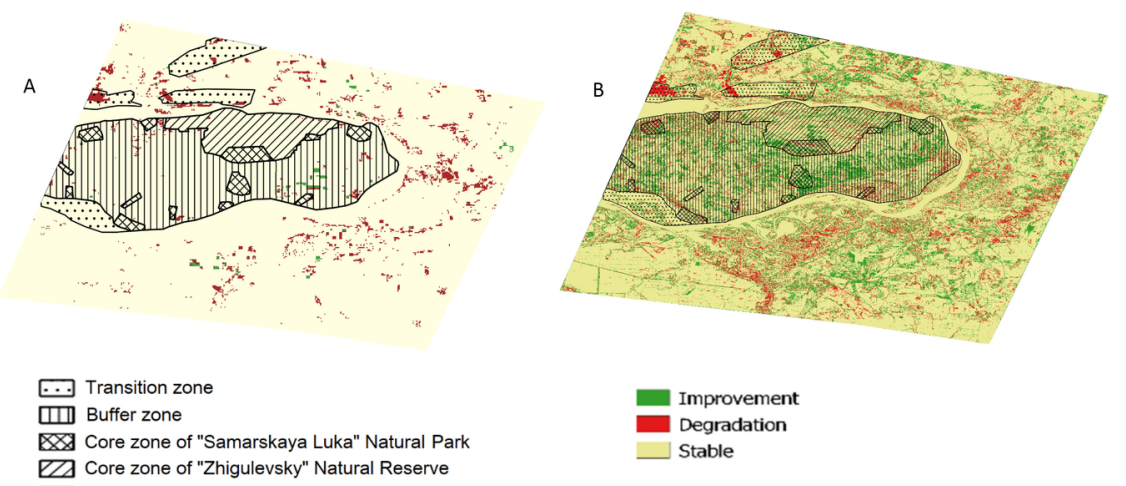
[D Core zone of "Zhigulevsky" Natural Reserve $\square$ Border of Natural reserves

Improvement - Stable
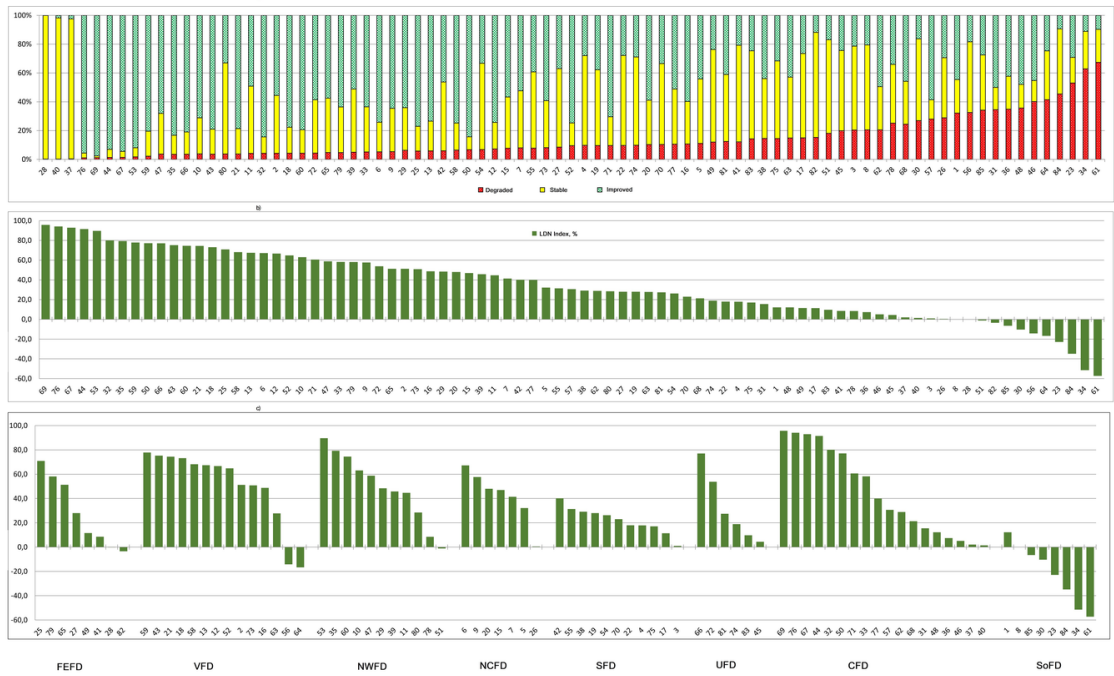

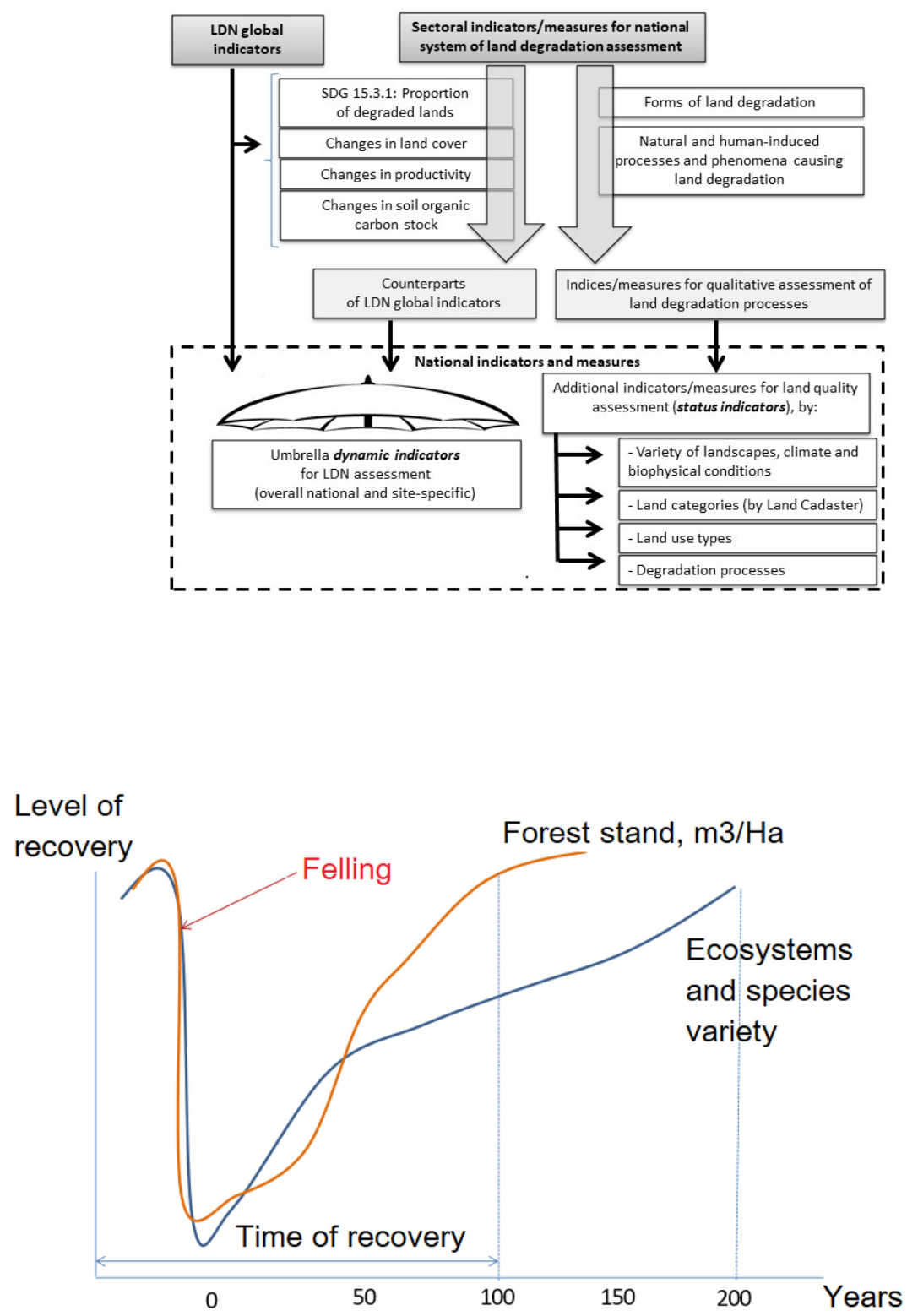


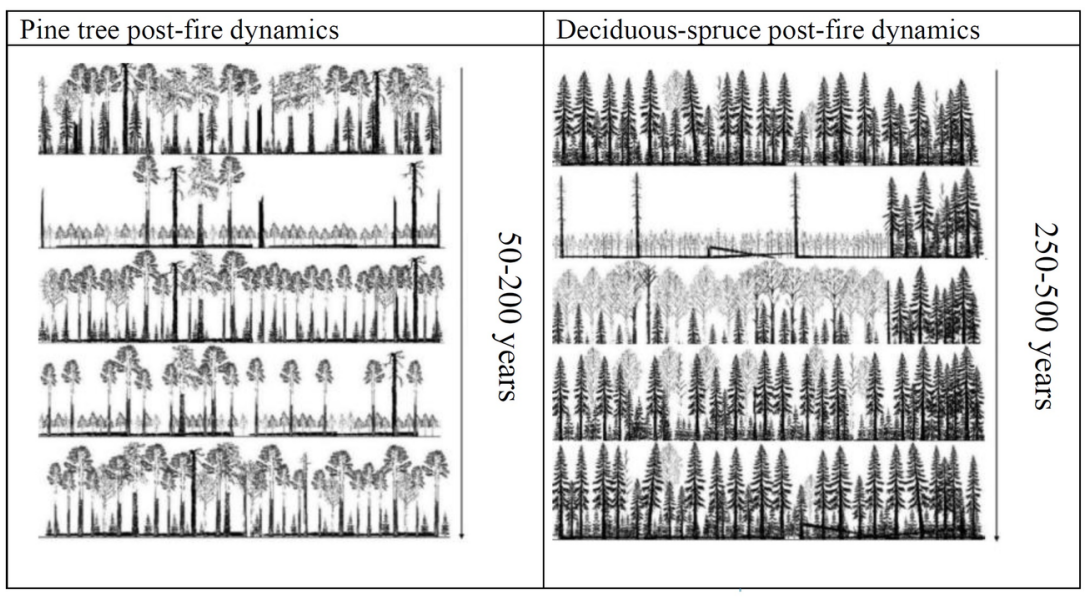

